\title{
Effect of Adding Polypropylene Fibers in Met Kaolin-Based Geopolymer Concrete
}

\author{
Qais J. Frieh*, Mushtaq H. Kamil \\ Civil Engineering Dept., University of Technology-Iraq, Alsina'a street, 10066 Baghdad, Iraq. \\ *Corresponding author Email: bce.19.77@grad.uotechnology.edu.iq
}

\section{H I G H L I G H T S}

- Adding fibers to geopolymer concrete improves the brittleness and its strength.

- The polypropylene fiber content boosts the compressive strength of geopolymer concrete.

- The density of geopolymer concrete was increased by adding polypropylene fibers.

- The workability of geopolymer concrete was decreased by adding polypropylene fibers.

\section{A R T I C L E I N F O}

Handling editor: Wasan I. Khalil

Keywords:

Geopolymers

Metakaolin

Alkaline Activators

Polypropylene

Compressive Strength

Density

\author{
A B S T R A C T
}

Geopolymer is a binder material that was created as a result of efforts to decrease Portland cement's negative environmental effects. Geopolymer concrete shares certain properties with ordinary concrete, including brittleness. Like ordinary concrete, geopolymer concrete, when exposed to stresses, cracks and fails under these stresses. The purpose of adding fibers to geopolymer concrete is to overcome the matrix's brittleness and enhance its strength (particularly flexural strength). This study used metakaolin, a range of alkaline activators, and different quantities of polypropylene fibers to produce geopolymer concrete. Metakaolin's chemical composition, workability, density, flexural and compressive strength of geopolymer concrete were all examined for the purpose of determining the effect of polypropylene fibers on geopolymer concrete. Polypropylene fibers were used to make the mixes, which were then added to the mix at various percentages of $0 \%, 0.5 \%$, and $1 \%$ of the total volume of concrete. The results of the experiments showed that increasing the polypropylene fiber content to $0.5 \%$ boosts the compressive strength of geopolymer concrete. On the seventh day, the compressive strength increased to $21 \%$. The density of geopolymer concrete was increased by adding polypropylene fibers, and there was a decrease in the workability with different fiber ratios.

\section{Introduction}

Geopolymers are green material since they are made from little processed natural ingredients or industrial leftovers, lowering their carbon footprint [1]. Geopolymers have attracted a lot of attention because of their quick strength growth [2], corrosion resistance [3], superior chemical resistance [4], low shrinkage rate, and freeze thaw resistance. To make geopolymer concrete of the needed strength, several mix proportioning methods based on the type of work, availability, quality of materials, field conditions, as well as workability and durability requirements are used. Although the geopolymers have numerous advantages over OPC, they also exhibit OPC-like strain failure behavior [5,6]. Fibers in concrete have been added to improve a range of concrete properties, including fracture resistance, ductility and fatigue resistance, as well as impact and wear resistance $[7,8]$.The addition of fibrous elements to concrete improves its structural integrity. Recent research has discovered that reinforcing concrete with polypropylene, nylon, or steel fibers can lower shear and tensile loads in critical structural regions $[9,10]$. The addition of twisted polypropylene bundles to OPC concrete improves its mechanical properties without increasing density [10]. In addition, adding nylon and polypropylene fibers to OPC concrete improved its engineering qualities, specifically its split tensile strength [11]. Similarly, adding fibers to concrete can greatly improve its flexural strength [12].In an alkaline environment, Poly-Vinyl-Alcohol fibers, on the other hand, are extremely stable. Recent research has shown that these fibers have a good connection to geopolymer matrices [13] and may be used to create composites with better impact toughness [14] and superior freeze-thaw cycle resistance [15].

Met kaolin was used as the basic material in this study. In a previous study, the properties of geopolymer concrete based on met kaolin were improved by replacing it with certain percentages of ordinary cement [16].PWhile polypropylene fibers were used to reinforce the geopolymer concrete. A mixture of sodium silicate solution and sodium hydroxide solution was 
utilized to react with aluminum and silicon in the met kaolin to form the paste that joined the aggregates and polypropylene fibers in the combination to form the geopolymer concrete. This paper also investigates the impact of polypropylene fibers on the density, workability, and compressive strength of geopolymers.

\section{Research Significance}

Previous research on geopolymer concrete reinforced with polypropylene fiber and based on Iraqi met kaolin has been restricted, despite the fact that met kaolin is widely available in Iraq. This study presents preliminary findings from studies using Iraqi met kaolin to make geopolymer concrete with polypropylene fibers.

\section{Research Methodology}

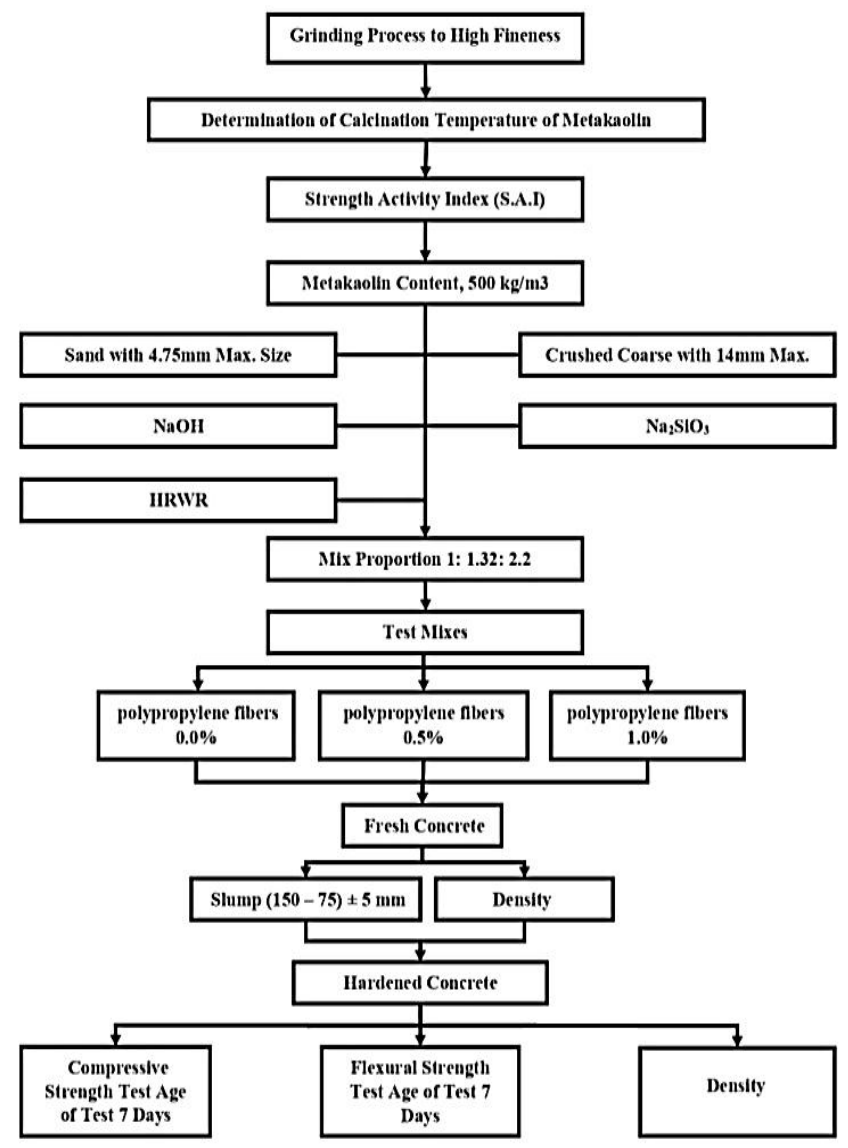

Figure 1: Details of the experimental program

\section{Materials}

The main component is metakaolin, which is sourced from the Dewekla site and meets ASTM C618-12a standards. The chemical composition of metakaolin as determined by the analysis is shown in Table(1), with silica oxide $\left(\mathrm{SiO}_{2}\right)$ accounting for $55.99 \%$, aluminum oxide $\left(\mathrm{Al}_{2} \mathrm{O}_{3}\right)$ for $38.32 \%$, iron oxide $\left(\mathrm{Fe}_{2} \mathrm{O}_{3}\right)$ for $1.735 \%$, and calcium oxide $(\mathrm{CaO})$ accounting for less than $0.7 \%$.

Table 1: XRD analysis data for met kaolin composition

\begin{tabular}{ll}
\hline Composition & Content (\%) \\
\hline $\mathrm{SiO}_{2}$ & 55.99 \\
$\mathrm{Al}_{2} \mathrm{O}_{3}$ & 38.32 \\
$\mathrm{Fe}_{2} \mathrm{O}_{3}$ & 1.735 \\
$\mathrm{CaO}$ & 0.671 \\
$\mathrm{MgO}$ & 0.19 \\
$\mathrm{~K}_{2} \mathrm{O}$ & 0.5344 \\
$\mathrm{SO}_{3}$ & 0.24 \\
$\mathrm{TiO}_{2}$ & 2.015 \\
\hline
\end{tabular}


The calcium silicate hydrate (CSH) gel is formed when metakaolin's silicon dioxide mixes with calcium hydroxide from the cement hydration process, resulting in cementitious compounds appropriate for usage in geopolymers. The presence of calcium ions resulted in a rapid reaction time. As a result, the geopolymer will harden quicker and cure faster [17].A mixture of a $12 \mathrm{M}$ sodium hydroxide solution and a sodium silicate solution is used to make the alkaline solution. $\mathrm{NaOH}$ granules (which comes in flakes and pellets) were dissolved in water at $98 \%$ purity to make the $\mathrm{NaOH}$ solution. The characteristics of $\mathrm{NaOH}$ are shown in Table (2)According to Table (3), the concentration of sodium silicate solution is influenced by the ratio of $\mathrm{Na}_{2} \mathrm{O}$ to $\mathrm{SiO}_{2}$ and $\mathrm{H}_{2} \mathrm{O}$. Table (4) shows the parameters of the polypropylene fibers employed in this study.

Table 2: Properties of Sodium hydroxide

\begin{tabular}{ll}
\hline Composition & Content (\%) \\
\hline $\mathrm{NaOH}$ & 98.00 \\
$\mathrm{Na}_{2} \mathrm{CO}_{3}$ & 0.40 \\
$\mathrm{NaCl}$ & 0.15 \\
$\mathrm{Fe}_{2} \mathrm{O}_{3}$ & 0.01 \\
$\mathrm{Na}_{2} \mathrm{SO}_{4}$ & $200 \mathrm{ppm}$ \\
$\mathrm{Cu}^{+2}$ & $4 \mathrm{ppm}$ \\
$\mathrm{Ni}^{+2}$ & $5 \mathrm{ppm}$ \\
$\mathrm{SiO}_{2}$ & $20 \mathrm{ppm}$ \\
\hline
\end{tabular}

Table 3: Properties of Sodium Silicate

\begin{tabular}{ll}
\hline Description & Value \\
\hline Ratio of $\mathrm{SiO}_{2}$ to $\mathrm{Na}_{2} \mathrm{O}$ & $2.4 \pm 0.05$ \\
$\mathrm{Na}_{2} \mathrm{O}$ percent by weight & $13.00-13.60$ \\
$\mathrm{SiO}_{2}$ percent by weight & $32.00-33.00$ \\
Density $-20^{\circ}$ & $50 \pm 0.5$ \\
Specific Gravity & $1.535-1.550$ \\
Viscosity (CPS) $20^{\circ} \mathrm{C}$ & $600-1200$ \\
pH & 12.9 \\
\hline
\end{tabular}

Table 4: Properties of Polypropylene Fibers

\begin{tabular}{ll}
\hline Property & Value \\
\hline Specific gravity & 0.91 \\
Diameter $(\mu \mathrm{m})$ & $15-20$ \\
Tensile strength $(\mathrm{MPa})$ & $600-700$ \\
Modulus of Elasticity $(\mathrm{GPa})$ & $6-9$ \\
Alkali resistance & Excellent resistance \\
Average aspect ratio & 65 \\
Length $(\mathrm{mm})$ & 12 \\
\hline
\end{tabular}

\section{Mixture design and specimen's preparation}

To prepare a Solution of $12 \mathrm{M} \mathrm{NaOH}$, In a volumetric flask, dissolve $\mathrm{NaOH}$ pellets in distilled water [18] for 24 hours, the $\mathrm{NaOH}$ solution is allowed to settle. The $\mathrm{NaOH}$ solution and the $\mathrm{Na}_{2} \mathrm{SiO}_{3}$ solution are combined after 24 hours [19]. When both are progressively blended and swirled, an exothermic reaction occurs, releasing a large amount of heat. The mixture is allowed to settle for 45 minutes to an hour. As a result, hand gloves are utilized as a safety precaution. Metakaolin and aggregates are dry mixed in geopolymer concrete samples. The alkaline activators are then added to the dry mix, which is then wet mixed for 3 to 4 minutes. Finally, polypropylene fibers are added to the wet mix in various amounts, such as $0 \%, 0.5 \%$, and $1.0 \%$. Geopolymer concrete reinforced with polypropylene fibers proportions are shown in Table (5).

Table 5: Mix proportions of GP reinforced with polypropylene fibers

\begin{tabular}{lllllll}
\hline $\begin{array}{l}\text { Mixes } \\
\text { symbol }\end{array}$ & $\begin{array}{l}\text { Metakaolin } \\
(\mathrm{g})\end{array}$ & $\begin{array}{l}\text { Coarse } \\
\text { aggregate } \\
(\mathbf{g})\end{array}$ & $\begin{array}{l}\text { Fine } \\
\text { aggregate } \\
(\mathbf{g})\end{array}$ & $\begin{array}{l}\text { Polypropylene } \\
\text { fibers ratio }\end{array}$ & $\begin{array}{l}\mathbf{N a O H} \\
(\mathrm{g})\end{array}$ & $\begin{array}{l}\mathrm{Na}_{2} \mathrm{SiO}_{3} \\
(\mathrm{~g})\end{array}$ \\
\hline PPF0 & 500 & 1100 & 720 & 0 & 250 & 250 \\
PPF0.5 & 500 & 1100 & 720 & 0.5 & 250 & 250 \\
PPF1 & 500 & 1100 & 720 & 1 & 250 & 250 \\
\hline
\end{tabular}


Fresh geopolymer with or without polypropylene fibers is poured into steel molds with dimensions of (100x100x100) mm cubes, $(100 \times 100 \times 400) \mathrm{mm}$ beams, and $(100 \times 200) \mathrm{mm}$ cylinders and compacted by a vibrating table. The samples are demolded after being placed in a laboratory environment at $60^{\circ} \mathrm{C}$ for 24 hours. After that, the samples are placed in an oven with sunlight until the testing day arrives. The weight of the samples was obtained after 7 days to measure the density and water absorption, and they were evaluated in a strength testing machine [20,21].

\section{Results and Discussion}

\subsection{Workability}

Figure 2 shows the slump test results of a freshly mixed geopolymer with and without polypropylene fibers. The workability value for a geopolymer mix without polypropylene fibers (PPF0) is $150 \mathrm{~mm}$. The workability value for a geopolymer mix containing 0.5 percent polypropylene fibers (PPF0.5) is 90mm. PPF1 (geopolymer mix with 1\% polypropylene fibers) has a workability rating of $75 \mathrm{~mm}$. The workability trend indicates that as the percentage of polypropylene fibers increases from (PPF0) to (PPF1), the workability values drop. This could be due to the polypropylene strands' ability to obstruct free flow. To summarize, the workability of polypropylene fibers reduces as the number of fibers grows [22].

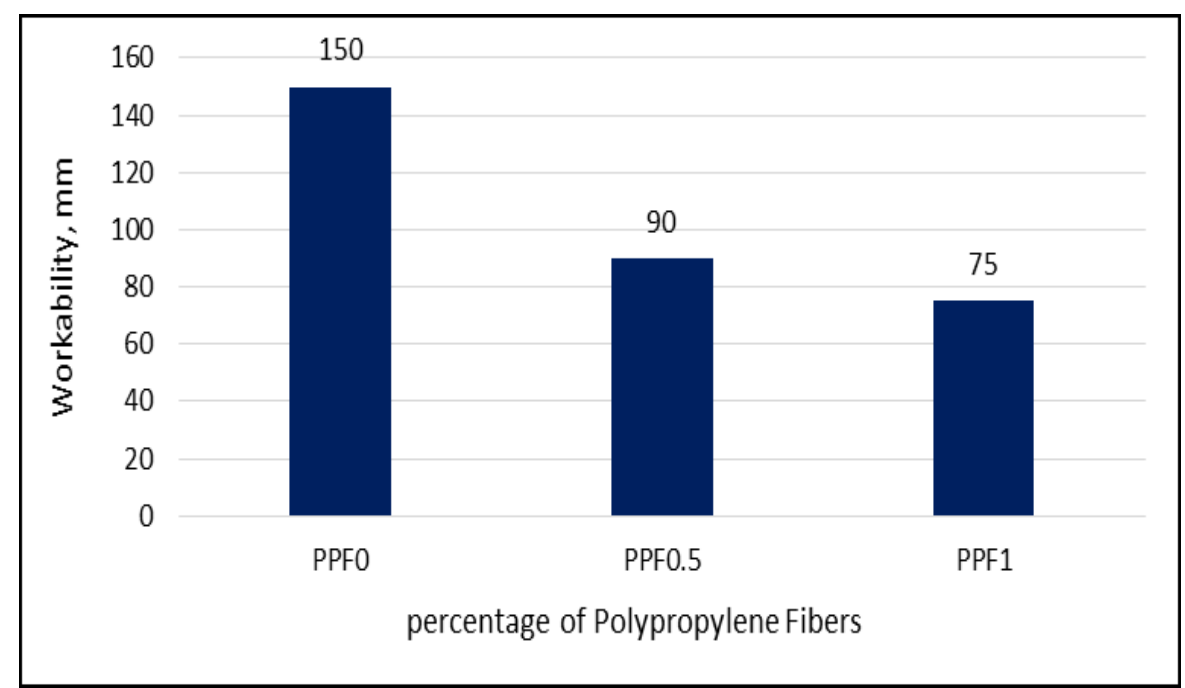

Figure 2: Workability graph for different percentage of polypropylene fibers

\subsection{Density}

Figure 3 illustrates the density of geopolymer concrete after seven days. The density values for PPF0, PPF0.5 and PPF1 are 2180,2190 and $2184 \mathrm{~kg} / \mathrm{m}^{3}$, respectively. Although the density increased in PPF0.5, it noted that the increase in the percentage of fibers caused balling and the formation of voids and gaps that led to a decrease in the density in PPF1, in addition, the excessive increase in fiber reduces the weight of the solid particles.

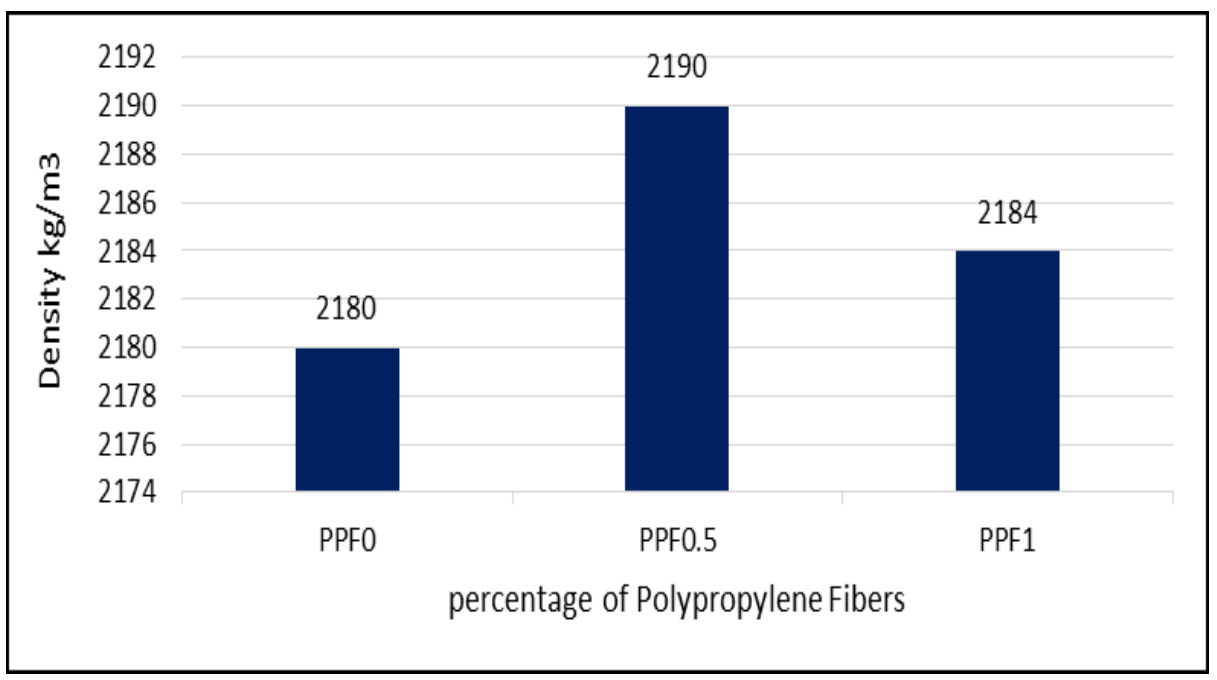

Figure 3: Density graph for different percentage of polypropylene fibers 


\subsection{Compressive Strength}

Figure 4 shows how the inclusion of polypropylene fibers affects the compressive strength of concrete as the age of the concrete increases. Figure 4 shows that at the age of 7 days, the pattern shows a little increase in strength from (PPF0) to (PPF0.5) and a decline in strength (PPF1). For 7 days, the compressive strengths of (PPF0, PPF0.5, and PPF1) were 24, 29.2 and 27.23 MPa, respectively. In comparison to (PPF0) concrete, compressive strength increases by 21.67 and $13.45 \%$ for (PPF0.5) and (PPF1), respectively.When polypropylene fibers were added, the compressive strength increased as well. As demonstrated in Figure 4, the compressive strength of (PPF0.5) increased over (PPF0), but decreased in (PPF1). This could be due to fiber's role in inhibiting the proliferation of microcracks by arresting their form in a the matrix. The addition of fiber increased the compressive strength of each geopolymer mixture. As a result, geopolymer concrete containing polypropylene fibers was more durable than geopolymer concrete without polypropylene fibers [23].

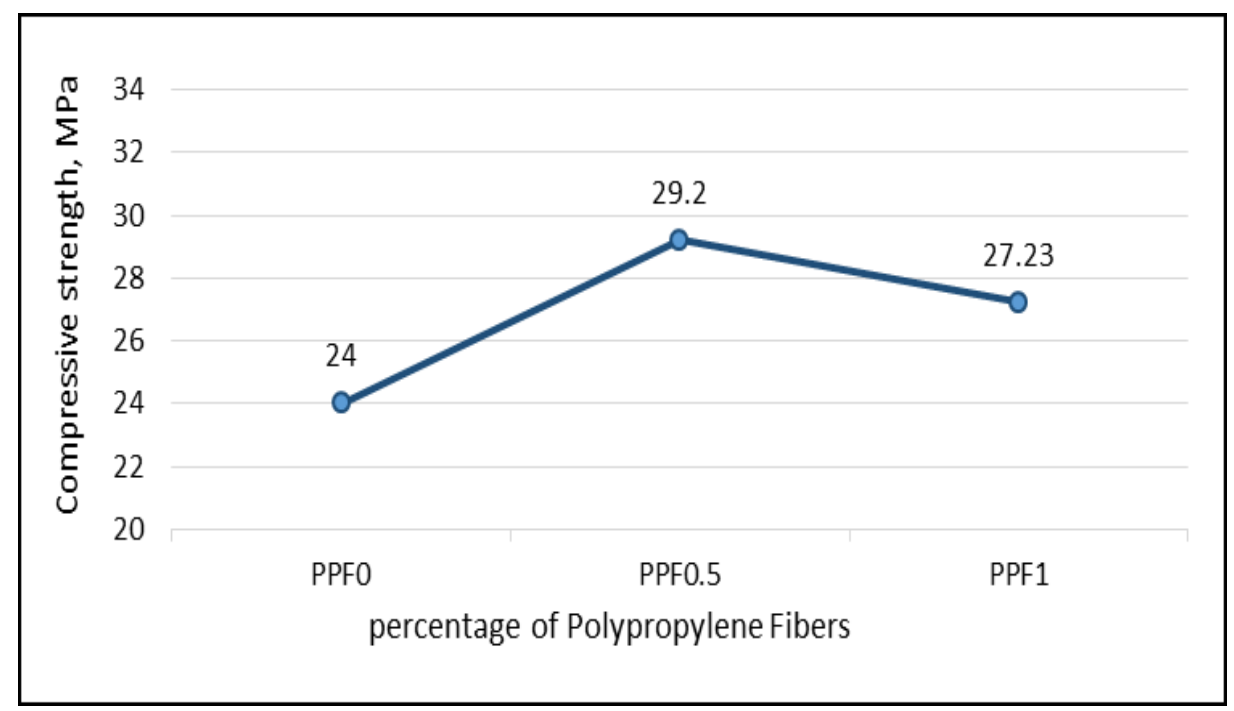

Figure 4: Compressive strength graph for different percentage of polypropylene fibers

\subsection{Flexural Strength}

At the age of seven days, all mixtures' flexural strength is assessed, and the findings are shown in Figure 5. and shows that the percent of flexural strength has increased, with the average strength of (PPF0, PPF0.5, and PPF1) being 4.62, 5.67 and 5.83 $\mathrm{MPa}$, respectively. This clearly demonstrates that adding polypropylene fibers to GPC improves its bending strength. The mechanical bond between the geopolymer and the fibers were improved, causing an increment in bending strength [24].

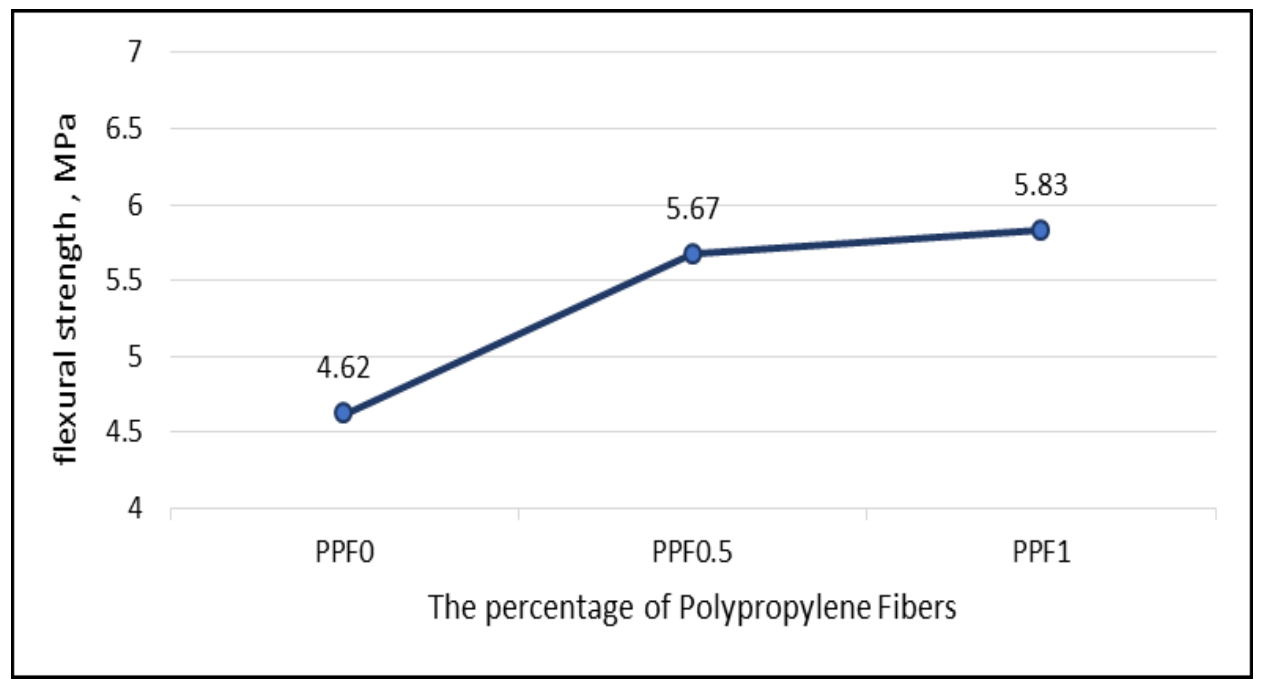

Figure 5: Flexural strength graph for different percentage of polypropylene fibers

\section{Conclusions}

The purpose of this study was to investigate the characteristics of geopolymer concrete reinforced with polypropylene fibers. The compressive and flexural strength of geopolymer concrete were influenced by the percentage of polypropylene fibers present. The compressive strength increased to some extent when the percentage of polypropylene fibers increases. At 7 days, the greatest compressive strength was found to be $29.2 \mathrm{MPa}$. Geopolymer concrete of $0.5 \%$ of fibers. For (PPF1), flexural strength increased by $26 \%$ when polypropylene fibers were added at $1 \%$ volume. Also, for (PPF0.5), the greatest 
density was reported to be $2190 \mathrm{~kg} / \mathrm{m} 3$ after 7 days. (PPF1) has the lowest value for workability, which had 75 mm. Adding polypropylene fiber has a detrimental impact on workability, but it has a favorable impact on strength and reduces porosity and increases density.

\section{Author contribution}

All authors contributed equally to this work.

\section{Funding}

This research received no specific grant from any funding agency in the public, commercial, or not-for-profit sectors.

\section{Data availability statement}

The data that support the findings of this study are available on request from the corresponding author.

\section{Conflicts of interest}

The authors declare that there is no conflict of interest.

\section{References}

[1] B. C.McLellan, R. P. Williams, J. Lay,A. van Riessen,G. D. Corder, Costs and carbon emissions for geopolymer pastes in comparison to ordinary portland cement, J. Cleaner. Prod.,19(2011)1080-1090. https://doi.org/10.1016/j.jclepro.2011.02.010

[2] A. M.Fernández-Jiménez,A. Palomo,C. López-Hombrados, Engineering properties of alkali-activated concrete, ACI. Mater. J., 103 (2006) 106-112.

[3] W. I. Khalil, Q. J. Frayyeh, and M. F. Ahmed, Characteristics of eco-friendlymetakaolin based geopolymer concrete pavement bricks, Eng. Technol. J., 38 (2020) 1705-1716. https://doi.org/10.30684/etj.v38i11A.1699

[4] T. Bakharev, Durability of geopolymer materials in sodium and magnesium sulfate solutions,, Cem. Concr. Res., 35 (2005) 1233-1246. https://doi.org/10.1016/j.cemconres.2004.09.002

[5] M. Reed, W. Lokuge, W. Karunasena, Fiber-reinforced geopolymer concrete with ambient curing for insitu applications, J. Mater. Sci., 49 (2014) 4297-4304. https://doi.org/10.1007/s10853-014-8125-3

[6] V. S. Kumar, B. S. Thomas, A. Christopher, An experimental study on the properties of glass fiberreinforced geopolymer, Int. J. Eng. Res. Appl., 2 (2012) 722-726.

[7] S.A. Bhalchandra, A.Y. Bhosle, Properties of glass fiber reinforced geopolymer concrete, IJMER ., 3 (2013) $2007-2010$.

[8] S.S. Patil and A.A. Patil, Properties of polypropylene fiber reinforced geopolymer concrete, IJCET ., 5 (2015) $2909-2912$.

[9] P. Shafigh, H. Mahmud, and M. Z. Jumaat, Effect of steel fiber on the mechanical properties of oil palm shell lightweight concrete, Mater. Des., 32 (2011) 3926-3932. https://doi.org/10.1016/j.matdes.2011.02.055

[10] M. K. Yew, H. B. Mahmud, B. C. Ang, and M. C. Yew, Influence of different types of polypropylene fibre on the mechanical properties of high-strength oil palm shell lightweight concrete, Constr. Build. Mater., 90 (2015) 36-43. https://doi.org/10.1016/j.conbuildmat.2015.04.024

[11] S. P. Yap, U. J. Alengaram, and M. Z. Jumaat, Enhancement of mechanical properties in polypropylene- and nylon-fiber reinforced oil palm shell concrete, Mater. Des., 49 (2013) 1034-1041. https://doi.org/10.1016/j.matdes.2013.02.070

[12] P. R. K. Chakravarthy, R. Janani, T. Ilango, and K. Dharani, Properties of concrete partially replaced with coconut shell as coarse aggregate and steel fibers in addition to its concrete volume, IOP Conference Series: Materials Science and Engineering, 183 (2017). https://doi.org/10.1088/1757-899X/183/1/012028

[13] Z. Li,Y. Zhang, and X.Zhou, Short fiber reinforced geopolymer composites manufactured by 2 extrusion, J. Mater. Civ. Eng., 17 (2005) 624-631. https://doi.org/10.1061/(ASCE)0899-1561(2005)17:6(624)

[14] Y. Zhang,W. Sun,Z. Li, Impact behavior and microstructural characteristics of PVA fiber reinforced fly ash-geopolymer boards prepared by extrusion technique, J. Mater. Sci., 41 (2006) 2787-2794. https://doi.org/10.1007/s10853-006-6293-5

[15] [15] Y.Zhang,W. Sun,Z. Li,X. Zhou,C. Chau, "Impact properties of geopolymer based extrudates incorporated with fly ash and PVA short fiber,Construction and Building Materials, 22 (2008) $370-383$. https://doi.org/10.1016/j.conbuildmat.2006.08.006

[16] [16] W. I. Khalil, Q. J. Frayyeh, H. T. Abed, Effect of ordinary portland cement on some properties of pervious geopolymer concrete, Eng. Technol. J., 39 (2021) 668-674. https://doi.org/10.30684/etj.v39i4A.1793 
[17] A.M. Al Bakri,H. Kamarudin,M. Bnhussain,K. Nizar,A.R. Rafiza,Y. Zarina, The processing,characterization, andproperties of fly ash based-geopolymer concrete, Rev. Adv. Mater. Sci., 30 (2012) 90-97.

[18] D.Hardjito, and B.V.Rangan, Development and properties of low-calcium fly ash-based geopolymer concrete Research Report GC1, Faculty of Engineering, Curtin Univ. of Technology, Perth, (2005).

[19] M.Komljenovi'c,Z. Bascarevic, and V.Bradic, Mechanical and microstructural properties of alkali-activated fly ash geopolymer, J. Hazard. Mater ., 181 (2010) 35-42. https://doi.org/10.1016/j.jhazmat.2010.04.064

[20] ASTM C78/C78M-15a Standard test method for flexural strength of concrete, American Society for Testing and Materials.

[21] ASTM C496/C496M-11 Standard test method for splitting tensile strength for cylindrical concrete specimens, American Society for Testing and Materials.

[22] L. Martinie, P. Rossi, N. Roussel, Rheology of fiber reinforced cementations materials: classification and prediction, Cem. Concr. Res., 40 (2010) 226-234. https://doi.org/10.1016/j.cemconres.2009.08.032

[23] V.S. Kumar, B.S. Thomas and A. Christopher, An experimental study on the properties of glass fiber reinforced geopolymer concrete, Int. J. Eng. Res. Appl., 2 (2012) 722-726.

[24] K. V. A. Pham, T. K. Nguyen, T. A. Le, et al, Assessment of performance of fiber reinforced geopolymer composites by experiment and simulation analysis, J. Appl. Sci., 9 (2019) 3424. https://doi.org/10.3390/app9163424 